\title{
Evaluation of Soil Fertilty Status and Fertility Indices of Bodi Block of Theni District in Tamilnadu, India
}

\author{
C. Abirami, S. dhivya, I. Gayathri, K.S. Glory, M.S. Keerthana, M. Kowsalya, \\ V.H. Neema, P. Srimathi, R. Elangovan, C. Krithika ${ }^{*}$ and M. Theradimani
}

Bodi Block of Theni District,Tamilnadu, India

*Corresponding author

\section{A B S T R A C T}

\begin{tabular}{|c|c|}
\hline Keywords & \\
\hline $\begin{array}{l}\text { Soil fertility, Bodi } \\
\text { block organic } \\
\text { carbon, pH, EC }\end{array}$ & $\begin{array}{l}\text { A study on soil fertility evaluation of Bodi block of Theni district of Tamil Nadu was } \\
\text { undertaken with a view to prepare a fertility map depicting the available nutrient status of } \\
\mathrm{N}, \mathrm{P}, \mathrm{K} \text {, organic carbon, } \mathrm{pH}, \mathrm{EC} \text { and nutrient index value of surface soil in various zones } \\
\text { to serve as a valuable tool to optimize nutrient level to crops for maximizing the yield of }\end{array}$ \\
\hline Article Info & $\begin{array}{l}\text { crops without causing stress on soil fertility status of Bodi block. We have selected twenty } \\
\text { five villages of Bodi block at random and surface samples were collected, processed and }\end{array}$ \\
\hline $\begin{array}{l}\text { Accepted: } \\
10 \text { May } 2019 \\
\text { Available Online: } \\
10 \text { June } 2019\end{array}$ & $\begin{array}{l}\text { analyzed for the available nutrient content of soils and a fertility map of major nutrients, } \\
\text { organic carbon, } \mathrm{pH} \text { and EC were developed and nutrient indices of major nutrients were } \\
\text { determined to have a precise estimate of fertility status. }\end{array}$ \\
\hline
\end{tabular}

\section{Introduction}

Bodinayakanur also known as Bodi Naickanur or shortened to just Bodi. It is a Town and a municipality in Theni district in the state of Tamil Nadu, India. It is geographically located between $10.02^{\circ} \mathrm{N}$ and $77.35^{\circ} \mathrm{E}$. Bodinayakanur is the second largest and most populated town in Theni district the town is the taluk headquarters. Due to the weather and natural environment, the first Prime Minister of India, Jawaharlal Nehru, called the town as "South Kashmir". It is located on the foothills of the Western Ghats, in the southern state of Tamil Nadu in India. This town is surrounded by the ranges of the Western Ghats on three sides. It is located on the Cochin-Madurai-Rameshwaram National Highway 85. Theni, the nearest market town is $16 \mathrm{~km}$ from Bodi.

Soil fertility is the term which represents the capacity of the soil to supply nutrients in adequate amount for the growth and development of plants. As human populations continue to increase, human disturbance of the earth's ecosystem to produce food and fibre will plays greater demand on soils to 
supply essential nutrients. Therefore, it's essential to increase the understanding of chemical, biological and physical properties and relationships in the soil plant atmosphere continuum that control nutrient availability.

The carbon level is continuously decreased that results in the loss of nutrient retention capacity of the soil. Around 10 times depletion of carbon in soils of India is observed for two more decades. Similarly nitrogen and phosphorous levels are also being decreased in the same soils because of the reason that injudicious application of fertilizers by the farmers in their soils. The $\mathrm{pH}$ and EC levels of the soils are being constantly changed by the above mentioned mismanagement practices.

In Bodi block, the farmers are aware about soil testing and their importance. They are adopting the technologies implemented in their block by the agricultural officers. The farmers gain knowledge and they are well versed in the recent technologies followed. Around 25 villages have been identified and we collected soil samples from these 25 villages. The collected samples were processed for analysis of nutritive values. An investigation was undertaken to estimate the nitrogen, phosphorous, potassium, $\mathrm{EC}, \mathrm{pH}$ and organic carbon status of soils of Bodi block of Theni district and a soil fertility map was prepared.

\section{Materials and Methods}

The method followed for the collection of surface samples of Bodi block of Theni district, laboratory method followed for the evaluation of soil fertility status by chemical soil test and followed for the evaluation of fertility indices and mapping of soil fertility status of Bodi block are summarized as follows.

\section{Selection of locations of soil samples}

Twenty five farmer's fields of Bodi block of Theni district selected and surface $(0-15 \mathrm{~cm})$ were collected and the details are presented in table I.

\section{Collection and preparation of soil samples}

In each of twenty five locations, soil samples of about one kilogram were collected separately at depth of $0-15 \mathrm{~cm}$ and were air dried in shade, powdered with a wooden mallet and sieved through $2 \mathrm{~mm}$ sieve. The material that passed through the sieve was taken up for the various analyses pertaining to the present study.

\section{Soil fertility analysis}

\section{Available nitrogen}

The available nitrogen content of the soil was estimated by the alkaline permanganate method (Subbiah and Asija, 1956) and the value expressed in $\mathrm{Kg} \mathrm{ha}^{-1}$.

\section{Available phosphorus}

The available phosphorus was estimated by Olsen's method (Olsen et al., 1954) and the value expressed in $\mathrm{Kg} \mathrm{ha}^{-1}$.

\section{Available potassium}

The available potassium in the soil was estimated in neutral normal ammonium acetate extract with an EEL flame photometer using $\mathrm{K}$ - filter and standard solutions of neutral normal ammonium acetate. The result expressed in $\mathrm{Kgha}^{-1}$.

\section{Soil reaction $(\mathrm{pH})$}

A soil - water suspension in the ratio of 1:2 was prepared and the $\mathrm{pH}$ was estimated using ELICO $\mathrm{pH}$ meter. 


\section{Electrical conductivity}

The electrical conductivity of the soil - water suspension used for determining the $\mathrm{pH}$ (4) was estimated by using ELICO Conductivity Bridge and the value expressed in milli $\mathrm{mho} / \mathrm{cm}$.

\section{Preparation of soil fertility map of Bodi Block}

Soil fertility map of Bodi Block is prepared by incorporating the soil test data (Ghosh and Hasan, 1980) by following the two methods

1. Categorizing the soils fertility status of Bodi block into low, medium and high and development of soil fertility maps for the use of fertilizer management based on soil fertility status.

2. Nutrient index value is calculated from the percentage of soil test values under low, medium and high available nutrient levels of $\mathrm{N}, \mathrm{P}, \mathrm{K}$ and organic carbon using the following equation (Ghosh and Hasan, 1979).

$$
\mathrm{NIV}=\frac{N l+2 N m+3 N k}{N l+N m+N h}
$$

where NIV $=$ (percentage of soil high in available nutrient $\times 3)+($ percentage of soil medium in available nutrients $\times 2$ ) + (percentage of soil low in available nutrients $\times 1) / 100$.

$\mathrm{Nl}, \mathrm{Nm}$ and $\mathrm{Nh}$ are the numbers of samples falling under the class of low, medium and high nutrient status and a given a weight of 1 , 2 and 3 respectively.

NIV > 2.33 is high in native supply NIV $1.33-2.33$ is medium in native supply NIV $<1.33$ is low in native supply.

\section{Results and Discussion}

\section{Soil fertility status of nitrogen}

The results of the mean available nitrogen content of the surface soils of twenty five villages of Bodi block was $136.1 \mathrm{Kg} \mathrm{ha}^{-1}$. The soil fertility class of the available nitrogen content was found to be low in surface soils. The available nitrogen content of the surface soil samples ranged from $77-261 \mathrm{Kg} \mathrm{ha}^{-1}$. The low level of available nitrogen in surface soil was found to be lack of use of organic manures and exclusion of legumes in crop rotation and high depletion of nutrients from soil due to intensive cultivation of commercial crops such as vegetables, banana, flowers and fruit crops. (Srivastava and Singh, 1996)

The soil fertility map of available nitrogen status of surface soil as depicted in fig.1 of Bodi block of Theni district revealed with a colour code of yellow indicated low in available nitrogen status. An integrated nitrogen management strategy might be followed in these areas for sustaining soil fertility for high productivity of crops.

\section{Soil fertility status of phosphorus}

The results of the mean available phosphorus content in Bodi block of surface soil was $51.04 \mathrm{Kg} \mathrm{ha}^{-1}$. The available phosphorus content of the surface soil ranged from 20-90 $\mathrm{Kg} \mathrm{ha}^{-1}$. Bodi block of Theni district depicted with a colour code of violet indicating high in available phosphorus status (Fig. 2).

\section{Soil fertility status of potassium}

The results of the mean available potassium content of the surface soils of twenty five villages of Bodi block was $457 \mathrm{Kg} \mathrm{ha}^{-1}$. The soil fertility class of the available potassium content was found to be low both in surface 
soils. The available potassium content of the surface soil samples ranged from $103-1150$ $\mathrm{Kg} \mathrm{ha}^{-1}$. The low level of available potassium in surface was found to be lack of use of optimum use of fertilizers and manures and high depletion of potassium from soil due to intensive cultivation of commercial crops such as vegetables, banana, flowers and fruit crops (Srivastava and Singh, 1996).

The soil fertility map of available potassium status of surface soil as depicted in fig. 3 of Bodi block of Theni district revealed with a colour code of yellow indicated low in available potassium status. An integrated potassium management strategy might be followed in these areas for sustaining soil fertility for high productivity of crops.

\section{Soil fertility status of organic carbon}

The results of the mean organic carbon content of the surface soils of twenty five villages of Bodi block was $0.58 \%$. The organic carbon content of the surface soil samples ranged from $0.35 \%$ and $0.75 \%$ (Fig. 4). Compared to this low fertility index present in Bodi block of Then district revealed with a color code of yellow indicated low in available organic carbon status.

\section{Soil pH}

The results of the mean $\mathrm{pH}$ content of the soils of Bodi block was 6.7. The $\mathrm{pH}$ value of the surface soil samples ranged from 5.5-7.9 (Fig. 5).

\section{Soil EC}

The EC of the surface soil samples ranged from $0.02 \mathrm{dSm}^{-1}$ and $0.89 \mathrm{dSm}^{-1}$. The results of the mean available EC of the surface of twenty five villages of Bodi block was 0.25 $\mathrm{dSm}^{-1}$ depicted in Figure 6.

Table.1 Villages selected for investigation

\begin{tabular}{|l|l|l|l|}
\hline S.NO & NAME OF THE VILLAGE & S.NO & NAME OF THE VILLAGE \\
\hline & BODI & 13 & KOOLAIYANUR \\
\hline $\mathbf{1}$ & MELACHOKANATHAPURAM & 14 & BOOTHIPURAM \\
\hline $\mathbf{2}$ & B.AMMAPATTI & 15 & SILAMARATHUPATTI \\
\hline $\mathbf{3}$ & KODANGIPATTI & 16 & DOMBUCHERRY \\
\hline $\mathbf{4}$ & UPPUKOTAI & 17 & B.MEENAKSHIPURAM \\
\hline $\mathbf{5}$ & PERUMALGOUNDANPATTI & 18 & RASINGAPURAM \\
\hline $\mathbf{6}$ & DURAIRAJAPURAM & 19 & KURANGANI \\
\hline $\mathbf{7}$ & SILAMALAI & 20 & KOTTAKUDI \\
\hline $\mathbf{8}$ & PALARPATTI & 21 & KUNDALANAICKANPATTI \\
\hline $\mathbf{9}$ & KAMARAJAPURAM & 22 & MANIYAMPATTI \\
\hline $\mathbf{1 0}$ & OOTHAMPARAI & 23 & SOLAIYUR \\
\hline $\mathbf{1 1}$ & SINGARAKOTTAI & 24 & MANICKAPURAM \\
\hline $\mathbf{1 2}$ & NAGALAPURAM & 25 & BODENDRAPURAM \\
\hline
\end{tabular}


Fig.1 Available nitrogen content of Bodi block

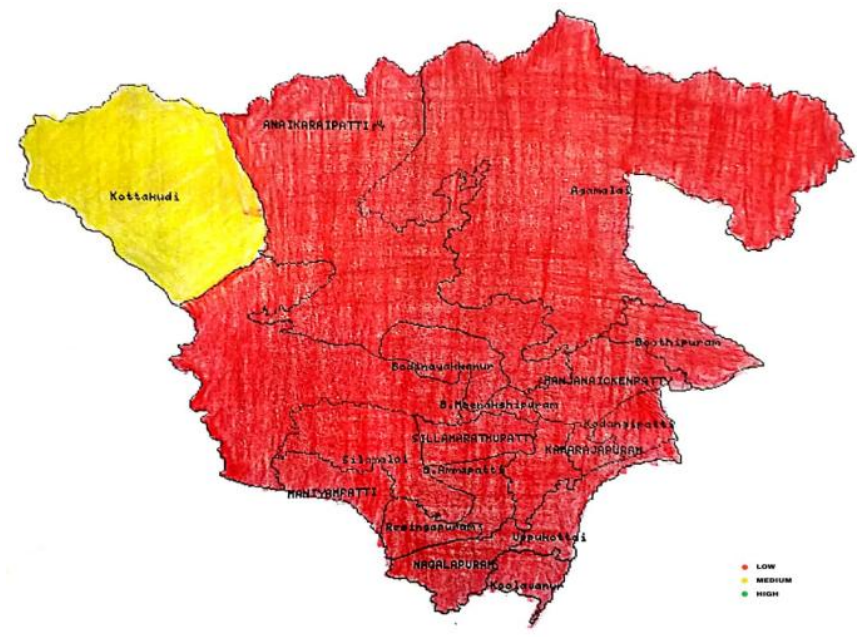

Fig.2 Available phosphorous content of Bodi block

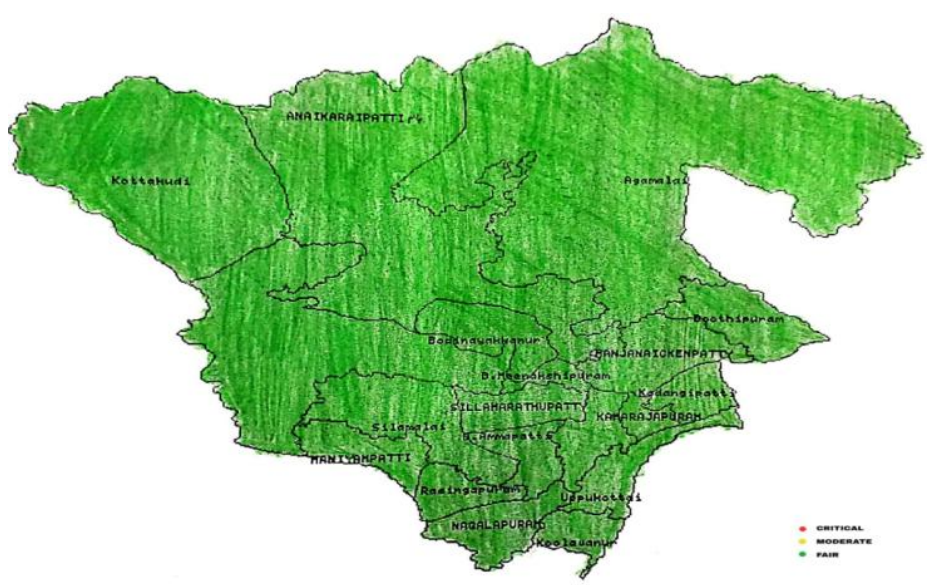

Fig.3 Available potassium content of Bodi block

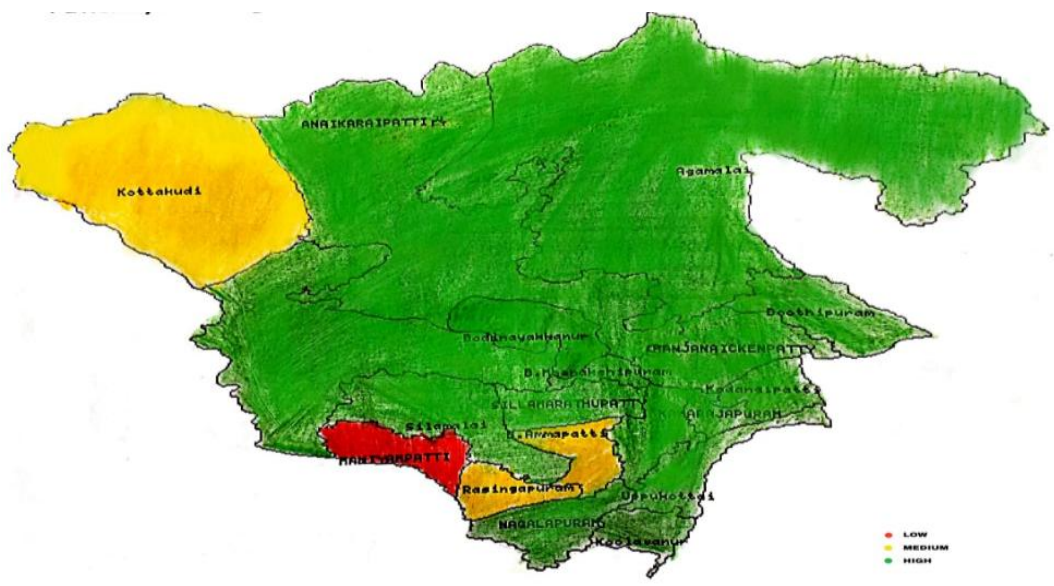


Fig.4 Available organic carbon content of Bodi block

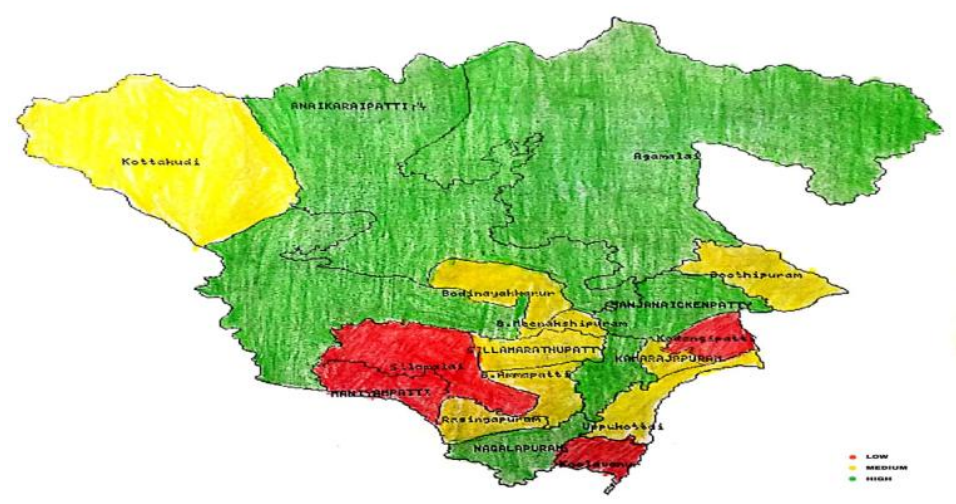

Fig.5 pH value of Bodi block

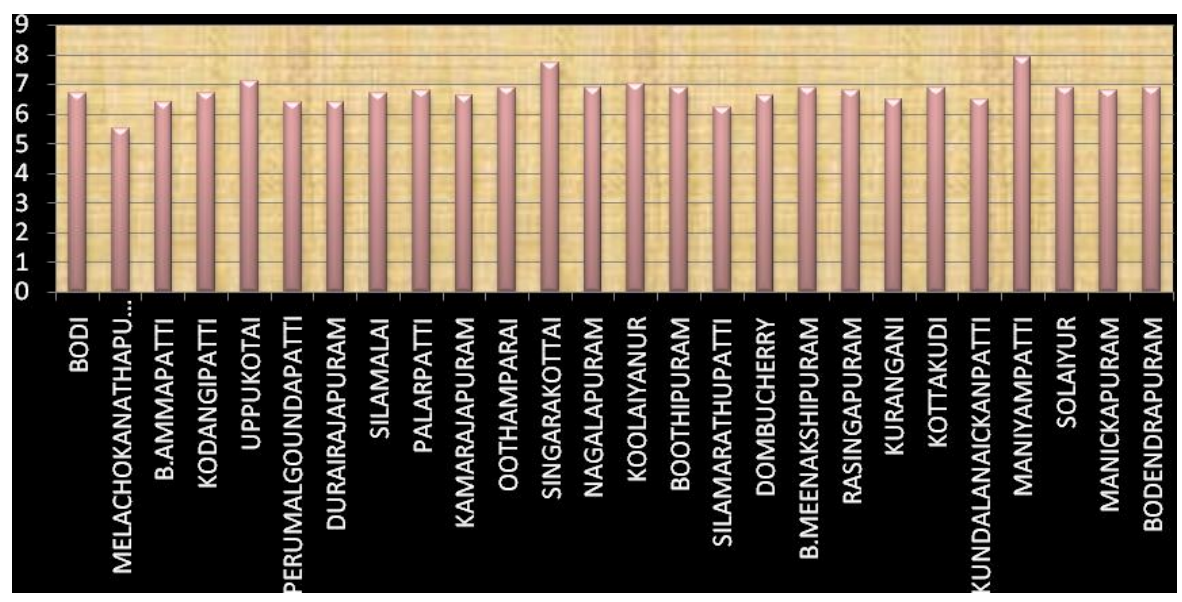

Fig.6 Electrical conductivity of Bodi block

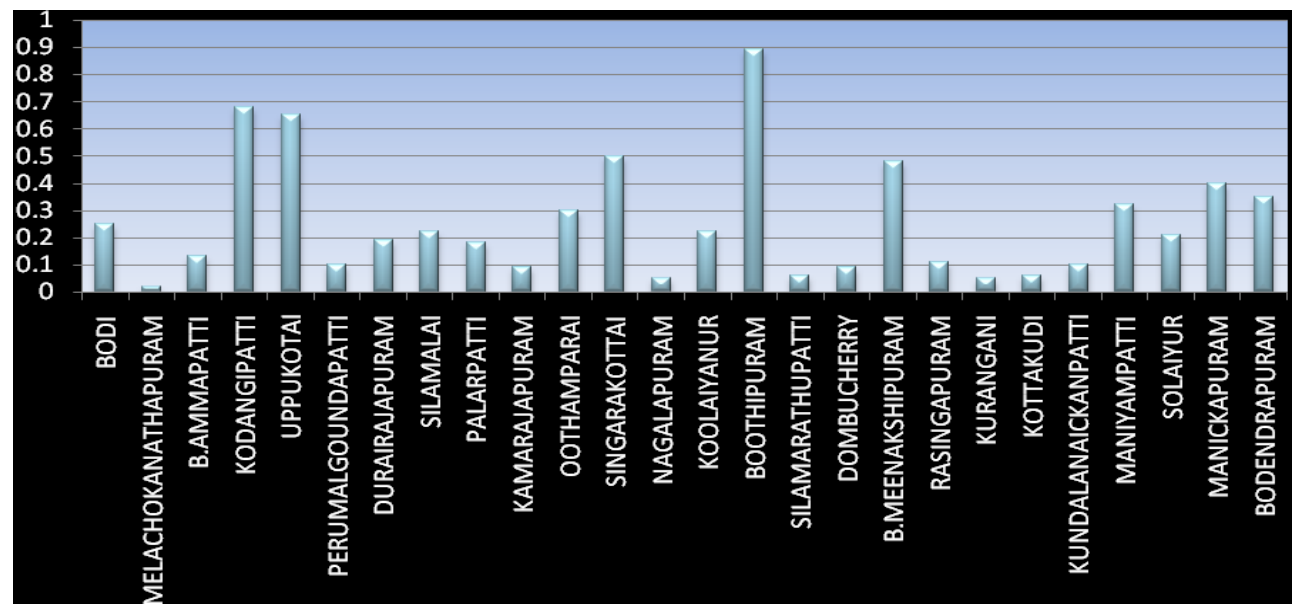


Nutrient Index Value:

NIV for Nitrogen $=$

$$
\begin{gathered}
\{(261.8 * 3)+(123.2 * 2)+(77 * 1)\} / 100 \\
=11.0
\end{gathered}
$$

NIV is High for Nitrogen

NIV for Phosphorus $=$

$$
\begin{array}{r}
\{(231 * 3)+(65 * 2)+(30.6 * 1)\} / 100 \\
=8.5
\end{array}
$$

NIV is High for Phosphorous

NIV for Potassium $=\{(1150 * 3)+(457 * 2)+$ $(103 * 1)\} / 100$

$$
=44.67
$$

NIV is High for Potassium

NIV For Organic Carbon $=$

$\{(0.75 * 3)+(0.63 * 2)+(0.35 * 1)\} / 100$ $=0.03$

NIV is Low for Organic Carbon

\section{References}

Ghosh, A.B., and R. Hasan.1979. Phosphorus Fertility Status of the Soils of India, Bull. No. 12. ISS, Pp. 1-8.

Ghosh, A.B., and R. Hasan.1980. Nitrogen Fertility Status of the Soils of India Fertilizer News 25 (11). P19-24.

Olsen, S. R., C.V. Cole, F.S. Watanabe and L.A. Dean .1954. Estimation of available phosphorus in soil by extraction with sodium carbonate. USDA Circ 939: 1-19.

Srivastava, P.C., and T.A. Singh.1996. Nitrogen in Soils and Transformation of Fertilizer Nitrogen In: Nitrogen Research and Crop Production (Tanden, H.L.S., Ed), Fertilizer Development and Consultation Organization, New Delhi. Pp14-31.

Subbiah, B.V., and L. Asija.1956. Arapid procedure for estimation of available nitrogen in soils. Curr. Sci. 25:259.

\section{How to cite this article:}

Abirami, C., S. dhivya, I. Gayathri, K.S. Glory, M.S Keerthana, M. Kowsalya, V.H Neema, P. Srimathi, R. Elangovan, C. Krithika and Theradimani, M. 2019. Evaluation of Soil Fertilty Status and Fertility Indices of Bodi Block of Theni District in Tamilnadu, India. Int.J.Curr.Microbiol.App.Sci. 8(06): 1072-1078. doi: https://doi.org/10.20546/ijcmas.2019.806.132 